\title{
The Use of Gamma Ray Computed Tomography to Investigate Soil Compaction Due to Core Sampling Devices
}

\author{
Luiz F. Pires, Robson C. J. Arthur, Vladia Correchel, Osny O. S. Bacchi, Klaus Reichardt, \\ Center for Nuclear Energy in Agriculture - CENA/USP, C.P. 96, 13.400-970, Piracicaba, SP, Brazil \\ and Rene P. Camponez do Brasil \\ Departament of Rural Engineering - ESALQ/USP, C.P. 9, 13.418-970, Piracicaba, SP, Brazil
}

Received on 8 September, 2003

\begin{abstract}
Compaction processes can influence soil physical properties such as soil density, porosity, pore size distribution, and processes like soil water and nutrient movements, root system distribution, and others. Soil porosity modification has important consequences like alterations in results of soil water retention curves. These alterations may cause differences in soil water storage calculations and matric potential values, which are utilized in irrigation management systems. Because of this, soil-sampling techniques should avoid alterations of sample structure. In this work soil sample compaction caused by core sampling devices was investigated using the gamma ray computed tomography technique. A first generation tomograph with fixed source-detector arrangement and translation/rotational movements of the sample was utilized to obtain the images. The radioactive source is ${ }^{241} \mathrm{Am}$, with an activity of $3.7 \mathrm{GBq}$, and the detector consists of a $3 \mathrm{in}$. $\mathrm{x}$ 3in. $\mathrm{NaI}(\mathrm{Tl})$ scintillation crystal coupled to a photomultiplier tube. Soil samples were taken from an experimental field utilizing cylinders $4.0 \mathrm{~cm}$ high and $2.6 \mathrm{~cm}$ in diameter. Based on image analyses it was possible to detect compacted regions in all samples next to the cylinder wall due to the sampling system. Tomographic unit profiles of the sample permitted to identify higher values of soil density for deeper regions of the sample, and it was possible to determine the average densities and thickness of these layers. Tomographic analyses showed to be a very useful tool for soil compaction characterization and presented many advantages in relation to traditional methods.
\end{abstract}

\section{Introduction}

Godfrey Hounsfield in 1971 developed the first computed tomograph (CT) for clinical purposes in nuclear medicine [1] and several advances have occurred in the last decades in this scientific field. The rapid growth in all forms of CT can be attributed mainly to more sophisticated computers capable to acquire and store large amounts of data, and provide a simple and straightforward means of analysis of these data. Since Hounsfield's work, CT can be found in several areas of knowledge like chemical and petroleum engineering, soil science and others. In soil physics CT can be used for soil water movement [2, 3], soil density [4], soil structure [5, 6] and soil compaction $[7,8,9]$ studies.

Soil compaction is an important parameter to identify possible modifications in the structure of soils due to anthropogenic and natural actions $[10,11]$. Soil compaction occurs when a compression process induces a decrease of the pore volume, with a consequent increase of soil density [8], causing strong modifications in soil structure and pore distribution. Compaction processes influence soil physical properties such as soil density, porosity, pore size distribution, therefore affecting soil water and nutrient movements, root system distribution, heat transfer, etc. Soil porosity modification has important consequences like alterations in soil water potential and, consequently, in the soil water re- tention curve. These alterations influence soil water storage calculations and matric potential values, which are utilized in irrigation management.

Camponez do Brasil [12], using five different soilsampling techniques showed that these techniques disturb the soil sample structure to some extend, and his results demonstrate the occurrence of a probable soil compaction due to the sampling process. He was, however, not able to identify and quantify the regions where this compaction occurs in the inner part of the soil sample since he did not count with a non-destructive technique suitable to investigate the problem. Having this in mind, this work was carried out in order to try the gamma ray CT technique as a tool to evaluate possible changes in soil structure caused by soil core sampling and to analyze the variations of soil bulk density within the soil sample volume.

\section{Computed Tomography}

CT represents the computation of the cross-sectional distribution of a physical property of a material from projections taken from a number of different directions. For the reconstruction of a tomographic image it is necessary to define plane or cut, through a coordinate system (x, y) utilized to locate measurement points. Mathematically, it is possible to 
define a function $\mathrm{f}(\mathrm{x}, \mathrm{y})$, called density function, which represents the cross-sectional distribution of the physical property of interest. The main objective of the $\mathrm{CT}$ is to reproduce as accurately as possible this function $\mathrm{f}(\mathrm{x}, \mathrm{y})$. For gamma ray $\mathrm{CT} f(\mathrm{x}, \mathrm{y})$ represents the linear attenuation coefficient $\mu$ $\left(\mathrm{cm}^{-1}\right)$ of material. The line integral of the function along $(\mathrm{r}, \phi)$ is called the sum ray or projection ray $\mathrm{P}(\mathrm{r}, \phi)$, given by:

$$
P(r, \phi)=\int_{r, \phi} f(x, y) d s
$$

where $\phi$ is the rotation angle of the $(\mathrm{x}, \mathrm{y})$ axes. This rotation of the axes can be obtained rotating the object in front of the radiation detector in fixed integer units of $\phi$. The term $r$ is the object translation movement in front of the detector and radiation source.

Through the application of the Beer-Lambert law it is possible to obtain:

$$
\ln \left(\frac{I_{0}}{I}\right)=\int_{r, \phi} \mu(x, y) d s
$$

where $\mathrm{I}_{0}$ and $\mathrm{I}$ are, respectively, the rates of the incident and the emerging photon beams, $\mu(\mathrm{x}, \mathrm{y})$ the linear attenuation coefficient at position $(\mathrm{x}, \mathrm{y})$, and ds a length element along the ray $\mathrm{r}$. When $\mathrm{f}(\mathrm{x}, \mathrm{y})$ is equal to $\mu(\mathrm{x}, \mathrm{y})$ it is possible to obtain, through the equations (1) and (2), a complete set of sum rays for a defined angle $\phi$, called projection. Acquiring a great number of sets of projections for different values of $\phi$ and through a computer analysis, it is possible to determine and to reconstruct the function $\mathrm{f}(\mathrm{x}, \mathrm{y})$ that provides a 2-D image of the object being submitted to the CT method [13].

\section{Material and Methods}

Soil samples were taken from a profile characterized as a red-yellow Latossol according to the Brazilian Soil Science Society classification, collected in an experimental field of the Department of Plant Production of ESALQ/USP, in Piracicaba, SP, Brazil (22 ${ }^{\circ} 4^{\prime} \mathrm{S} ; 47^{\circ} 38^{\prime} \mathrm{W}$; 580m above sea level).

CT analysis was performed on 5 undisturbed soil samples collected at soil surface using steel cylinders $4.0 \mathrm{~cm}$ high and $2.6 \mathrm{~cm}$ external diameter. The soil sampler device consists of an inox steel structure $4.2 \mathrm{~cm}$ high and $2.7 \mathrm{~cm}$ internal diameter, which permits the introduction of the aluminum cylinder in its inner space. Through of a rubber mass falling from different heights it is possible to introduce the steel cylinder into the soil. After the removal of the excess of soil around the steel cylinder the soil sample can be used for density evaluation. In this process it is important to be careful with the impacts of the rubber mass to minimize effects on the structure of the soil sample.

The CT equipment consists of a first generation system with a fixed source-detector arrangement, with translation/rotational movements of the sample. The radioactive gamma ray source is ${ }^{241} \mathrm{Am}$ with an activity of $3.7 \mathrm{GBq}$ emitting monoenergetic photons of $59.54 \mathrm{keV}$. The detector is a 3 in $\mathrm{x} 3$ in $\mathrm{NaI}(\mathrm{Tl})$ scintillation crystal coupled to a photomultiplier tube. Circular lead collimators of $1 \mathrm{~mm}$ were adjusted to both source and detector. Angular steps of $\phi$ were $2.25^{\circ}$ until completing a scan of $180^{\circ}$, with linear steps $\mathrm{r}$ of $0.14 \mathrm{~cm}$. Acquired data were stored in a PC and a reconstruction algorithm called Microvis [14] developed by Embrapa Agricultural Instrumentation (CNPDIA) was used to obtain CT images. The calibration of the CT system was obtained through linear correlation between linear attenuation coefficients and tomographic units (TU) of different materials $[15,16]$. The tomographic images of the soil samples were taken for vertical planes crossing the center of the cylindrical sample. TU values were converted to soil density values through equation (3):

$$
\rho_{s}=\frac{T U}{\alpha \cdot\left[\left(\frac{\mu_{s}}{\rho_{s}}\right)+\left(\frac{\mu_{w}}{\rho_{w}}\right) \cdot U\right]}
$$

where $\alpha$ represents the slope of CT calibration curve, $\left(\mu_{s} / \rho_{s}\right)$ and $\left(\mu_{w} / \rho_{w}\right)\left(\mathrm{cm}^{2} \cdot \mathrm{g}^{-1}\right)$ are the mass attenuation coefficients of the soil and water, respectively, and $U\left(g . g^{-1}\right)$ the gravimetric soil water content.

\section{Results and Discussion}

The value of $\alpha$ was $0.9233 \mathrm{~cm}$ and the linear regression coefficient of the calibration curve was 0.996 . The mass attenuation coefficients for the soil and water were $0.24429 \pm 0.00250 \mathrm{~cm}^{2} \cdot \mathrm{g}^{-1}$ and $0.18890 \pm 0.00018$ $\mathrm{cm}^{2} . \mathrm{g}^{-1}$, respectively, for the $59.54 \mathrm{keV}$ photons, which are in accordance to values found in the literature.

Two images of soil samples obtained by CT are shown on Fig. 1. These images represent soil samples with the same soil water content, which were collected using the described soil core sampler. The planes of image acquisition were vertical and the available data permitted a continuous analysis of the density distribution along the soil sample, in 2-D.

It can be observed through image analysis that the soil sampler induces a soil compaction next to the cylinder wall and at the bottom region of the soil sample. This can be observed by the contrast between the center, the border and the bottom of the sample indicating an increase of soil bulk density from the center to the border and bottom.

The observed compaction in the border and in the bottom of the soil sample can cause problems during soil water retention curve determinations if samples are used for this purpose. This compaction causes modifications in soil porosity and consequently in soil water retention characteristics. The water retention curve determined using such altered soil samples would not be reliable and not representative of the natural soil profile in the field. A poor soil water retention curve can lead to important practical problems of water management of irrigated crops.

Figure 2 allows a better visualization of the soil bulk density variation along transects within the sample, both in depth and along the width. 


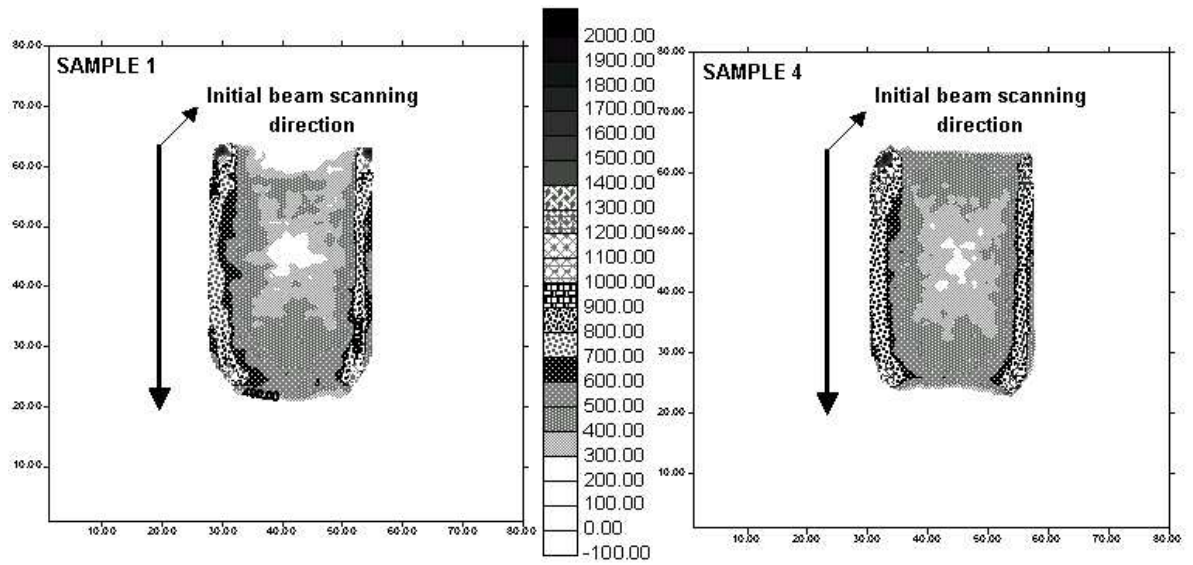

Figure 1. Tomographic images of soil samples obtained through the software "Microvis" developed by EMBRAPA/CNPDIA.

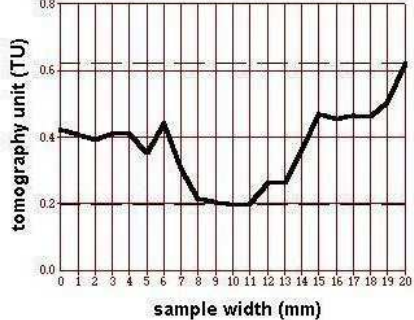

(A)

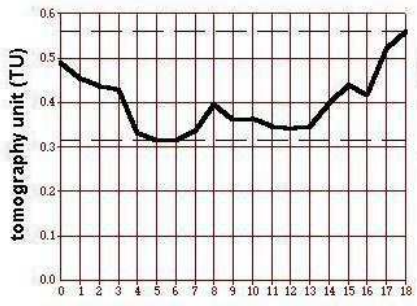

sample width $(\mathrm{mm})$

(C)

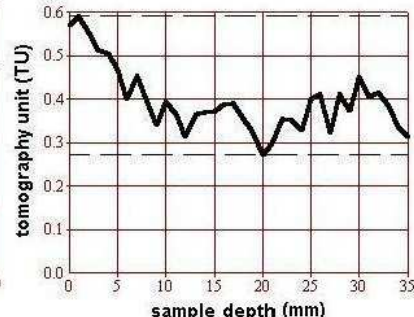

(B)

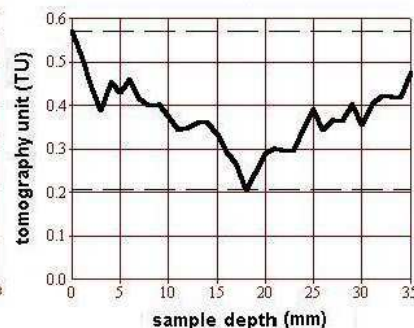

(D)
Figure 2. Analysis by transect for samples 1 and 4. (A and C) Represent transects obtained along the width of soil samples 1 and 4 and (B and D) Represent transects obtained along the depth, for the same samples.

The results shown in figure 2 refer to samples 1 and 4, however the same behavior was also observed for the other samples. The analysis of transects is only possible by CT. In depth it permits to confirm the occurrence of a compaction in the bottom of the samples, which is the case of samples 1 and 4 as a consequence of soil sampling process. Horizontal transects confirm the occurrence of more compacted zones next to the cylinder wall due to sampling, in contrast to the natural soil bulk density found in the center zone of the sample. These differences in soil bulk density along the horizontal transects indicate variations in soil porosity which, consequently can lead to differences in soil water retention. A probable cause of this compaction is the small diameter of the sampling cylinders. Block diagrams of samples 1 and 4 (Fig. 3) confirm the data obtained by the horizontal transect analysis. Tomographic unit results shown in these diagrams represent TU average values of thin vertical layers of the order of $3 \mathrm{~mm}$.

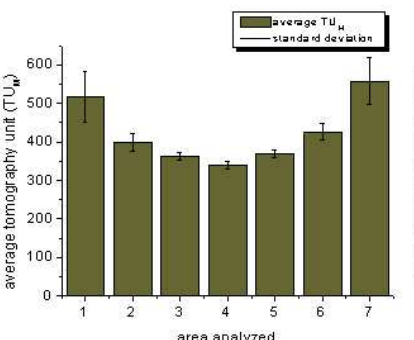

(A)

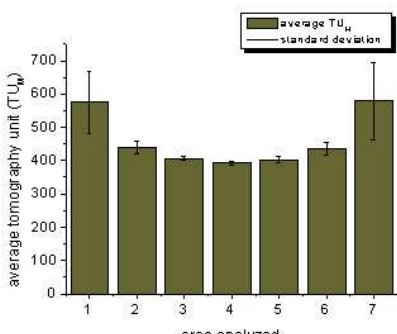

(B)
Figure 3. Histogram of average tomographic unit values obtained for samples 1 and 4. Areas in abscissa axis represent average TU values of thin layers of the order of $3 \mathrm{~mm}$.

Soil densities obtained for sample 1 were $1.79 \pm 0.12$ g.cm ${ }^{-3}$ (left border), $1.89 \pm 0.11 \mathrm{~g} . \mathrm{cm}^{-3}$ (right border) and $1.43 \pm 0.06$ g.cm ${ }^{-3}$ (center of soil sample). For sample 4 the values were $1.95 \pm 0.05 \mathrm{~g} . \mathrm{cm}^{-3}$ (left border), $1.96 \pm 0.06$ g.cm ${ }^{-3}$ (right border) and $1.59 \pm 0.06 \mathrm{~g} . \mathrm{cm}^{-3}$ (center of soil sample). In relation to compaction at the bottom of soil sample the values of soil density obtained for samples 1 and 4 were $2.01 \pm 0.04$ g.cm ${ }^{-3}$ and $2.07 \pm 0.05$ g.cm ${ }^{-3}$. These densities are larger than those determined in not compacted regions by CT for samples 1 and $4,1.53 \pm 0.01 \mathrm{g.cm}{ }^{-3}$ and $1.60 \pm 0.10$ g.cm ${ }^{-3}$, confirming compaction in the inferior surface of soil sample.

\section{Acknowledgements}

To FAPESP (grants no. 02/05066-5) for financial support.

\section{References}

[1] G.N. Hounsfield, Br. J. Radiol. 46, 1016 (1972).

[2] S. Crestana, S. Mascarenhas, and R.S. Pozzi-Mucelli, Soil Sci. 140, 326 (1985)

[3] D. Wildenschild, J.W. Hopmans, C.M.P. Vaz, M.L. Rivers, D. Rikard, and B.S.B. Christensen, J. of Hydrology 267, 285 (2002). 
[4] A.M. Petrovic, J.E. Siebert, and P.E. Rieke, Soil Sci. Soc. Am. J. 46, 445 (1982)

[5] S. Crestana, C.M.P. Vaz, Soil Till. Res. 47, 19 (1998).

[6] L. Farber, G. Tardos, and J.N. Michaels, Powder Techn. 132, 57 (2003).

[7] R.T. Lopes, A.P. Bessa, D. Braz, and E.F.O. Jesus, Appl. Rad. Isot. 50, 451 (1999).

[8] L. Fante Junior, J.C.M. Oliveira, L.H. Bassoi, C.M.P. Vaz, A. Macedo, O.O.S. Bacchi, K. Reichardt, A.C. Cavalcanti, and F.H.B.B. Silva, R. Bras. Ci. Solo. 26, 835 (2002).

[9] L.F. Pires, J.R. Macedo, M.D. Souza, O.O.S. Bacchi, and K. Reichardt, Appl. Rad. Isot. 59, 17 (2003).

[10] M. Pagliai, S. Rousseva, N. Vignozzi, C. Piovanelli, S. Pellegrini, and N. Miclaus, Ital. J. Agron. 2, 11 (1998).

[11] A. Marsili, P. Servadio, M. Pagliai, N. Vignozzi, Soil Till. Res. 49, 185 (1998).
[12] R.P. Camponez do Brasil, "Influência das técnicas de coleta de amostras na determinação das propriedades físicas do solo", MSc. Thesis, ESALQ/USP-Brazil 2000.

[13] G.T. Herman, 1980, Image Reconstruction from Projections, ed. 1, London, Academic Press.

[14] EMBRAPA/CNPDIA, 2000, "Microvis - Programa de Reconstrução e Visualização de Imagens Tomográficas, Guia do Usuário".

[15] F.A.M. Cássaro, "Tomografia de dupla energia simultânea para caracterização física de um meio poroso deformável", MSc. Thesis, IF/USP-Brazil 1994.

[16] L.F. Pires, J.R. Macedo, M.D. Souza, O.O.S. Bacchi, K. Reichardt, Appl. Rad. Isot. 57, 375 (2002). 